\title{
Crumbling the rising super-cancer of obesity by optimizing frequency and timing of food meals
}

\begin{abstract}
This public policy article establishes an innovative science based on which the rising risk of obesity as a major cancer in today's lifestyle can be minimized by optimizing circadian frequency and timing of food meals. Increasing the number of meals and decreasing meal size must be designed for day time. No major food meals must be left for evening and night time and instead fruits and vegetables should be taken overnight.
\end{abstract}

Keywords: obesity, cancer, eating frequency, meal timing, public health
Volume 2 Issue 6 - 2015

\author{
Akbar Nikkhah \\ Department of Animal Sciences, University of Zanjan, Iran
}

Correspondence: Akbar Nikkhah, Chief Highly Distinguished Professor, Department of Animal Sciences, University of Zanjan, National Elite Foundation, Iran, E-mail anikkha@yahoo.com

Received: May II, 2015 | Published: July 23, 2015

\section{Introduction}

The recent discoveries have set the stage for creating a new circadian science to optimize timing and frequency of food meals over the 24-h period. ${ }^{1-5}$ This is to minimize risks from accelerated obesity development and related metabolic disorders such as diabetes, immune deficiency and inferior quality of life. Impaired glucose tolerance and increased insulin resistance are most likely to occur overnight when thus no major energy-producing food meals must be taken. ${ }^{6-8}$

From an evolutionary perspective, human like other diurnal animals has evolved to be active during day and rested or asleep overnight, thus burning nutrients mainly during morning through early to late afternoon. ${ }^{9-11}$ This evolutionary trend warns against eating large evening meals. ${ }^{12}$ Instead, food meals must be designed and scheduled to be consumed mostly during day when the body has enough capacity to utilize and oxidize nutrients to generate energy for use by different cells. ${ }^{13,14}$

To avoid sharp rises in insulin release and thus to reduce likelihood of insulin resistance, large and main food meals must be broken down into multiple smaller meals. Such mini-meals must be distributed over the day time from early morning through late afternoon or the latest by early evening. This nutritional program smoothens the endocrinology involved in managing glucose and other nutrients metabolism. As a result, intermediary metabolism will be less likely to be disturbed by food meals. The cascade can reduce risks of obesity and diabetes. ${ }^{14,15}$

To overcome the evening and nocturnal crave for food, low-energy fruits and vegetables can be taken during evening and night. Soft sugar-free drinks are also optimal options to facilitate gastrointestinal function, heart performance and kidneys work. Abiding by such a circadian regimen may be difficult especially during early days, but it gradually becomes easier to be adhered to. Thus, persistence and patience must be exercised for the expected success of the program to be timely and lastingly realized. A fitting physical activity schedule is required as well to enhance the efficacy of the circadian food regimen.

\section{Conclusion}

The increasing global development of obesity has jeopardized individual and public health such dramatically that obesity is increasingly referred to as a devastating super-cancer. Optimizing circadian frequency and timing of major food meals as well as fruits and vegetables is a pragmatic doable approach to help minimize risks of obesity and related metabolic disorders and to improve life quality.

\section{Acknowledgements}

The Iran's Ministry of Science Research and Technology, National Elite Foundation and University of Zanjan are thanked for supporting the author's global programs of optimizing science edification in the new millennium.

\section{Conflict of interest}

The author declares no conflict of interest.

\section{References}

1. Nikkhah A. Establishing rhythmic regularities in cell physiology: A novel global program to thwart cancer. J Nutr Health Food Eng. 2015;2(2):1-2.

2. Nikkhah A. Timing of eating a global orchestrator of biological rhythms: dairy cow nitrogen metabolism and milk fatty acids. Biol Rhythms Res. 2014;45(5):661-670.

3. Nikkhah A. Secure Weight Management via Fitting Circadian Patterns of Physical Activity, Resting and Eating. Adv Obes Weight Manag Control. 2015;2(4):23.

4. Nikkhah A. Effective Weight Management in Periparturient Women through Optimizing Eating Timing: A Novel Global Approach. Adv Obes Weight Manag Control. 2015;2(3):18.

5. Nikkhah A. Circadian Fitting of Exercise and Eating Patterns: The Secret of Healthy Life. J Bioprocess Biotech. 2015;5:e129.

6. Nikkhah A. Harmonizing Eating and Exercise Circadian Rhythms for Optimal Glucose-Insulin and Vascular Physiology. Int J Diabetol Vasc Dis Res. 2015;3(3):87-88.

7. Nikkhah A. Discovering the Right Time to Take Food to Smash Diabetes. J Diabetes Res Ther. 2015;1.1.

8. Nikkhah A. Intake Circadian Physiology: An Overlooked Public Health Concern. Endocrinol Metab Synd. 2015;4:153.

9. Nikkhah A. Perspective: Nutrient Intake Chronophysiology: A Rising Public Health Concern. J Nutr Therap. 2014;3(4):156-157.

10. Nikkhah A. Eating time modulations of physiology and health: life lessons from human and ruminant models. Iran J Basic Med Sci. 2012;15(4):891-899. 
11. Nikkhah A. Time of Feeding an Evolutionary Science. Germany: Lap Lambert Publishing, GmbH \& Co; 2012. 192 p.

12. Nikkhah A. Avoid Large Night Meals to Stay Fit. J Obes Weight Loss Ther. 2015;4:e115.

13. Nikkhah A. Disease Closure through Opening Novel Chrono-Sciences: Bioprocessing of Intermediary Metabolism. J Bioprocess Biotechniq. 2014;5:1.
14. Nikkhah A. Timing of Eating to Eradicate Diabetes: A Feasible Prescription. J Diabetes Metabolism. 2014;5:8.

15. Nikkhah A. When to Eat to Beat Obesity and Diabetes? Journal of Diabetes and Metabolism. 2014;5:e115. 